\title{
Effect of full flavor and denicotinized cigarettes exposure on the brain microvascular endothelium: a microarray-based gene expression study using a human immortalized BBB endothelial cell line
}

Pooja Naik', Ravi K Sajja', Shikha Prasad' and Luca Cucullo ${ }^{1,2^{*}}$

\begin{abstract}
Background: Tobacco smoke (TS) toxicity to the brain microvasculature is still an understudied area till date. NF-E2 related factor (Nrf2) is a key transcription factor responsible for activating the antioxidant response element (ARE) genes following an oxidative insult. Till date, several studies targeting the blood brain barrier (BBB) have shown some protective role of Nrf2 in ischemia-reperfusion (IR) injury, however, its functional role in chronic smokers subjected to a life-long oxidative stress has never been addressed. This is of crucial importance since smokers have a much higher risk for cerebrovascular stroke and tobacco smoke exposure has been clearly shown to enhance BBB damage following an ischemia/reperfusion injury. Thus, the goal of our study was to investigate the defense pathways activated at the BBB endothelial level by TS exposure. Specifically we focused on Nrf2 and nuclear factor kappa-light-chainenhancer of activated $B$ signaling response $(N F-\kappa \beta)$ as the central protective mechanisms related to oxidative insult.

Results: With the exception of Nicotine, both full flavor (3R4F) and decotinized (ULN) cigarettes activated Nrf2 and $N F \kappa \beta$ pathways in hCMEC/D3 endothelial cells. Several detoxification and anti-oxidant genes including downstream products were also activated including NAD(P)H dehydrogenase quinone 1 (NQO-1), heme oxygenase-1 (HMOX-1), catalytic and modifier subunits of glutamate-cysteine ligase (GCL), solute carrier-SLC7A11). Gene expression levels of cytochrome P450s (CYP2S1 and CYP51A1) and efflux transporters P-glycoprotein (P-gp) and multi-drug resistance protein-4 (MRP4) were also enhanced. Increase of P-gp functional activity and depletion of GSH were also observed. Strikingly, toxicity of denicotinized ("reduced exposure") cigarettes was equivalent to 3R4F (or worse).

Conclusions: This study provides a detailed analysis of Nrf2-related cytoprotective mechanisms activated in response to $3 \mathrm{R} 4 \mathrm{~F}$ and ULN-derived TS exposure correlating the results with their oxidative and inflammatory potential. Toxicants present in soluble cigarette smoke extracts (CSE) and not nicotine seem to be the primary determinant of vascular toxicity. In this respect our results from this and previous studies suggest that chronic TS exposure can overcome Nrf2 and NFkB-p65 dependent cytoprotective mechanisms of the brain microvascular endothelium possibly leading to BBB impairment and loss of BBB integrity.
\end{abstract}

Keywords: Environment, Endothelium, Blood brain barrier, Inflammation, Transcriptomics, Alternative

\footnotetext{
*Correspondence: luca.cucullo@ttuhsc.edu

${ }^{2}$ Center for Blood Brain Barrier Research, Texas Tech University Health

Sciences Center, Amarillo, TX 79106, USA

Full list of author information is available at the end of the article
} 


\section{Background}

Tobacco smoke (TS) is the leading cause of premature preventable death worldwide. Smoking kills nearly 6 million over the world with 480,000 deaths in United States alone [1, 2]. Smoking attributable deaths have been largely associated to the pathogenesis of several complications such as cancer, ischemic heart disease and chronic obstructive pulmonary disease (COPD) [1]. However, equally significant but often neglected are the effects of chronic smoking on the onset and progression of several neurological and neurovascular complications such as Alzheimer's disease, multiple sclerosis and cerebral stroke [3-5]. Although epidemiological studies establish cigarette smoking as a major risk factor for the onset and progression of these diseases; till date the precise mechanisms underlying these irreversible deleterious changes to the brain and brain vasculatures are poorly understood.

Tobacco smoke consist of several thousand toxic compounds (including nicotine) capable of inducing oxidative stress and vascular inflammation triggering several pathophysiological changes in peripheral vasculatures $[6,7]$. Specifically to the blood brain barrier (BBB); we have clearly demonstrated that (1) TS can degrade membrane expression of essential tight junction (TJ) proteins such as ZO-1 and occludin; (2) it can induce a vascular inflammatory response in BBB endothelial cells (ECs) via release of Interleukin-6 (IL-6) and matrix metalloproteinase-2 (MMP-2); (3) it can up-regulate vascular adhesion molecules such as vascular adhesion molecule-1 (VCAM-1) and platelet endothelial cell adhesion molecule-1 (PECAM-1). All together, the data clearly suggest that TS can severely impair and compromise BBB integrity and function [8-10].

Moreover, we have also clearly demonstrated that oxidative stress is one of the cardinal determinants of TS induced $\mathrm{BBB}$ toxicity where the extent of $\mathrm{BBB}$ damage positively correlates with the oxidative capacity of the TS product tested. Several reduced exposure 'light' versions of tobacco products are currently available in market that claim to be safe solely on the reduction of nicotine or a few selected toxicants. Profiling of TS showed a significant release of reactive oxygen (ROS), hydrogen peroxide content and reactive nitrogen species (RNS) in the nicotine-free (NF, "reduced-exposure" brand) and ultralow nicotine products along with the full flavor products. As the level of $\operatorname{tar}, \mathrm{H}_{2} \mathrm{O}_{2}$ and nitric oxide content increased; TS induced $\mathrm{BBB}$ toxicity increased proportionally along with the level of pro-inflammatory activity and oxidative stress.

Thus we further investigated the role of oxidative stress and anti-oxidant mechanisms (such as NF-E2 related factor-Nrf2-signaling pathway) activated at the BBB endothelium in response to TS exposure. This is one of the main protective mechanisms triggered to counteract oxidative insult such as those elicited by TS [11].

Although microarray based gene expression studies investigating TS induced global changes in cellular transcriptome have been previously reported in human bronchial epithelium, oral mucosa and peripheral immune cells [12-15]; the effect of TS on BBB endothelium has only be marginally addressed and even more so at the level of gene expression and transcription. Moreover, a comprehensive study focussing on TS activated antioxidant mechanisms at the BBB is still lacking. In this study we addressed this critical issue using human BBB endothelial cells (hCMEC/D3 cell line) [16] chronically exposed to various TS related products over a period of 24 h. Nrf2 expression and its downstream pathway targets were also assessed and correlated with respect to oxidative and/or inflammatory potential of the specific tobacco product.

For this purpose, we performed a side-by-side comparative analysis of antioxidant mechanisms triggered by nicotine exposure against soluble cigarette smoke extracts (CSE) from: (1) regular full flavor cigarette (3R4F) and (2) reduced exposure ultra-low nicotine cigarette (ULN). About 43,000 gene targets were screened in a microarray based gene expression studies. Positive hits from the gene array data were investigated further using real time PCR (mRNA) and western blot analysis (proteins expression level) as well as ad hoc functional studies. In summary, our work provides an in depth detailed analysis of the BBB counteractive cellular mechanisms triggered by realistic exposure to TS.

\section{Results \\ CSE increases oxidative stress load and Nrf2 nuclear translocation in BBB endothelium}

Main and side stream TS contain high levels of toxic reactive aldehydes and pro-oxidants that are shown to destabilize the cellular redox balance. We assessed the impact of TS generated from different tobacco products, on cellular ROS levels (oxidative stress load) in BBB endothelium using CellROX Green Reagent. As shown in Figure 1a, exposure to CSE from both full flavor (3R4F) and ULN cigarettes rapidly increased endothelial ROS (as early as $3 \mathrm{~h}$ post-exposure), with greater intensity of fluorescence, compared to control. In comparison, exposure to nicotine elicited only a mild oxidative response (Figure 1a).

Next, we determined the effects of TS on endothelial Nrf2 expression and its nuclear translocation (Figure 1bd). Nrf2 is a redox-sensitive transcription factor and a master regulator of cellular redox homeostasis. It has been demonstrated that increased levels of ROS trigger 


\section{a}

Control
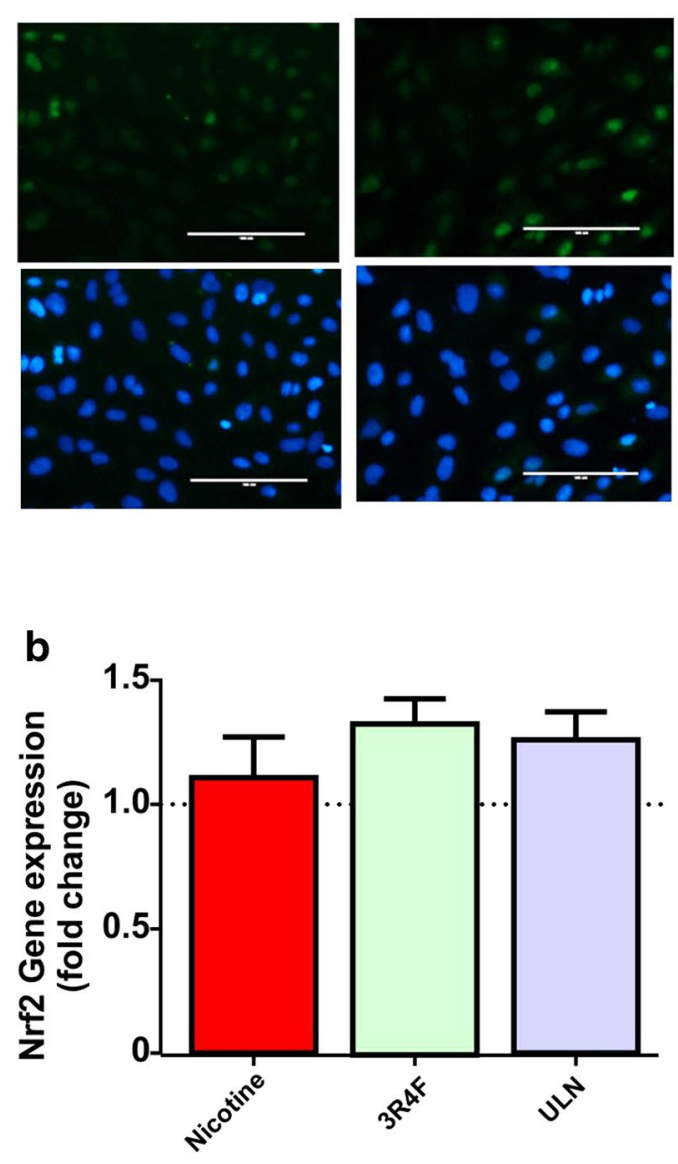

d

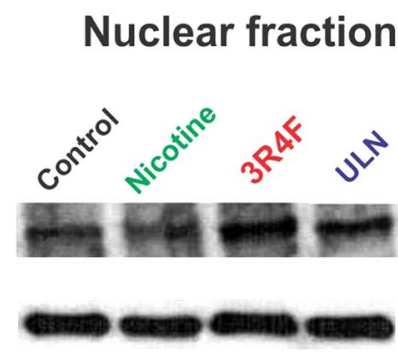

\section{Nicotine}

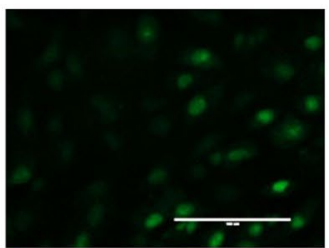

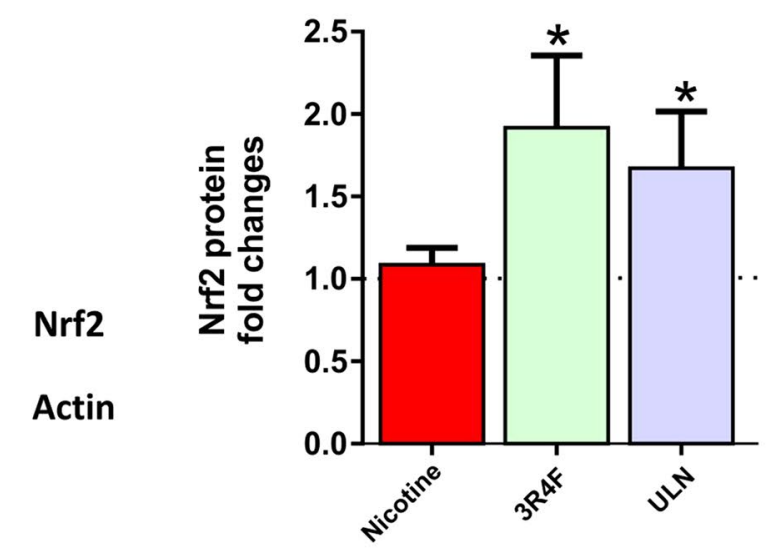

Figure 1 CSE exposure potentiates oxidative stress responses in BBB endothelial cells. Briefly, confluent hCMEC/D3 cell monolayers were exposed to media containing nicotine only $(100 \mu \mathrm{g} / \mathrm{mL}$ ) or CSEs from full flavor (3R4F) or ULN tobacco products containing nicotine equivalent to $100 \mathrm{ng} /$ $\mathrm{mL}$ ). Fresh media without nicotine or mainstream TS served as controls. a Immunofluorescence analysis of cellular ROS levels (an indicator of oxidative stress load) were determined by using CellROX ${ }^{\circ}$ Green reagent following exposure to CSE or nicotine treatment ( 3 h); $\mathbf{b}$ gene array based analysis of Nrf2 gene expression changes was determined after control, nicotine or TS exposure $(n=6)$; c Nrf2 mRNA expression was quantified by RT-PCR using primer specific sequences $(n=4)$; $\mathbf{d}$ Nrf2 expression and nuclear translocation following exposure to different conditions at early time point of $8 \mathrm{~h}$ as analyzed by western blotting. Representative western blots were shown with actin as a loading control. Data were expressed as mean \pm SEM (fold change over control; $n=4$ biological replicates). ${ }^{*} p<0.05$ vs. control. 
the activation and subsequent nuclear translocation of Nrf2. This ultimately triggers the expression/activation of various molecular networks primarily involved in cellular cytoprotection against oxidative and inflammatory stress $[11,17]$. To this end, our data showed modest increase in Nrf2 gene expression levels in response to CSE from 3R4F and ULN cigarettes (Figure 1b). However, Nrf2 transcription assessed by RT-PCR was significant in BBB endothelial cells exposed to ULN-derived CSE ( $<<0.05$; compared to control) but not in cultures exposed to CSE derived from 3R4F cigarettes (Figure 1c) Interestingly, Nrf2 nuclear translocation (Figure 1d) was statistically significant in BBB ECs exposed to either ULN and 3R4F cigarette extracts. Nicotine exposure did not affect Nrf2 gene expression (Figure 1b) nor Nrf2 transcription (Figure 1c) or its nuclear translocation (Figure 1d). This further supports its relatively modest impact on cellular oxidative stress levels observed in Figure 1a.

\section{CSE up-regulates Nrf2-ARE dependent phase I detoxification genes}

As shown in Figure 2a, both microarray and RT-PCR analyses revealed a significant induction of NQO1 gene (a major enzyme of Phase I detoxification) both by 3R4F and ULN products $(\mathrm{p}<0.01$ and $\mathrm{p}<0.0001$ vs control fold change respectively), but not nicotine. Accordingly, exposure to $3 \mathrm{R} 4 \mathrm{~F}$ and ULN upregulated NQO1 protein expression as demonstrated by immunofluorescence and western blotting (Figure $2 \mathrm{~b} ; \mathrm{p}<0.05$ and $\mathrm{p}<0.01$ for
3R4F and ULN, respectively). Notably, the up-regulation of NQO1 expression by ULN was comparable to that achieved by 3R4F.

\section{CSE exposure augments transcription of Phase I cytochrome $\mathrm{P} 450$ s detoxification genes}

Cytochrome P450 (CYP450) family related enzymes provide additional layer of counter-regulatory anti-oxidant response through metabolism-based detoxification of toxic chemicals [18]. Although there is no specific report of CYP51A1 with respect to smoke toxicants, CYP2S1 has been reported to scavenge xenobiotics especially carcinogens present in TS [19]. As shown in Figure 3a, we observed a striking up-regulation in the gene expression of the CYP enzymes CYP2S1 (Figure 3a, $\mathrm{p}<0.001$ and $\mathrm{p}<0.01$ vs. control, for 3R4F and ULN respectively) which was also confirmed by RT-PCR (Figure 3b, $\mathrm{p}<0.05$ and $\mathrm{p}<0.001$ vs. control for 3R4F and ULN respectively). CYP51A1 gene expression was also up-regulated however; the measured changes were statistically significant only for BBB endothelial cultures exposed to ULN but not for 3R4F-derived CSE (Figure 3a). Corresponding RT-PCR measurements of the gene transcription showed only a modest increased but not to a significant level in either case. Note also that none of the changes in either gene expression or gene transcription for both enzymes failed to translate in a corresponding increase in protein expression (see Figure 3c). No effect at any level (gene expression, transcription and translation) was observed in response to nicotine exposure.

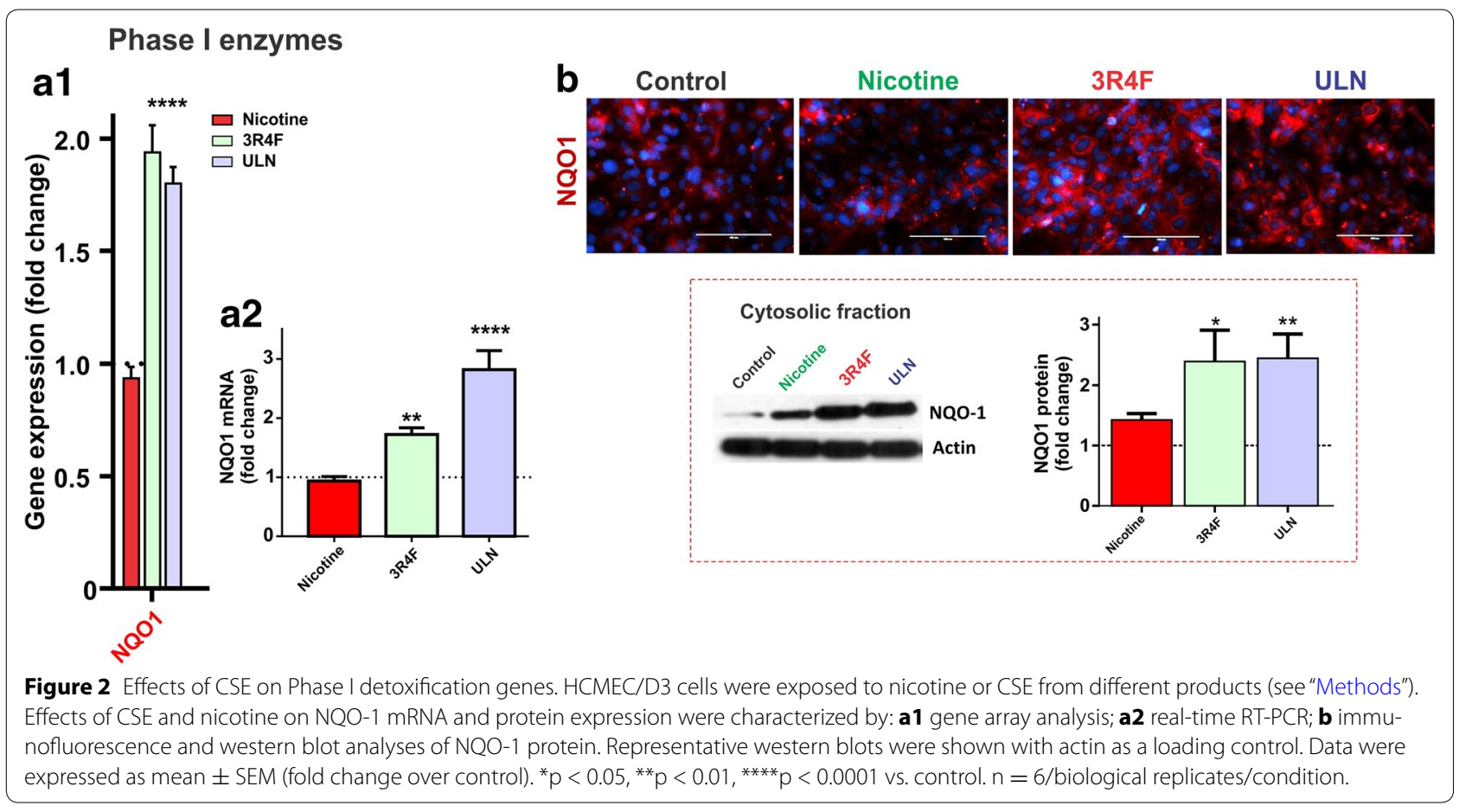




\section{Phase I CYP450 enzymes}
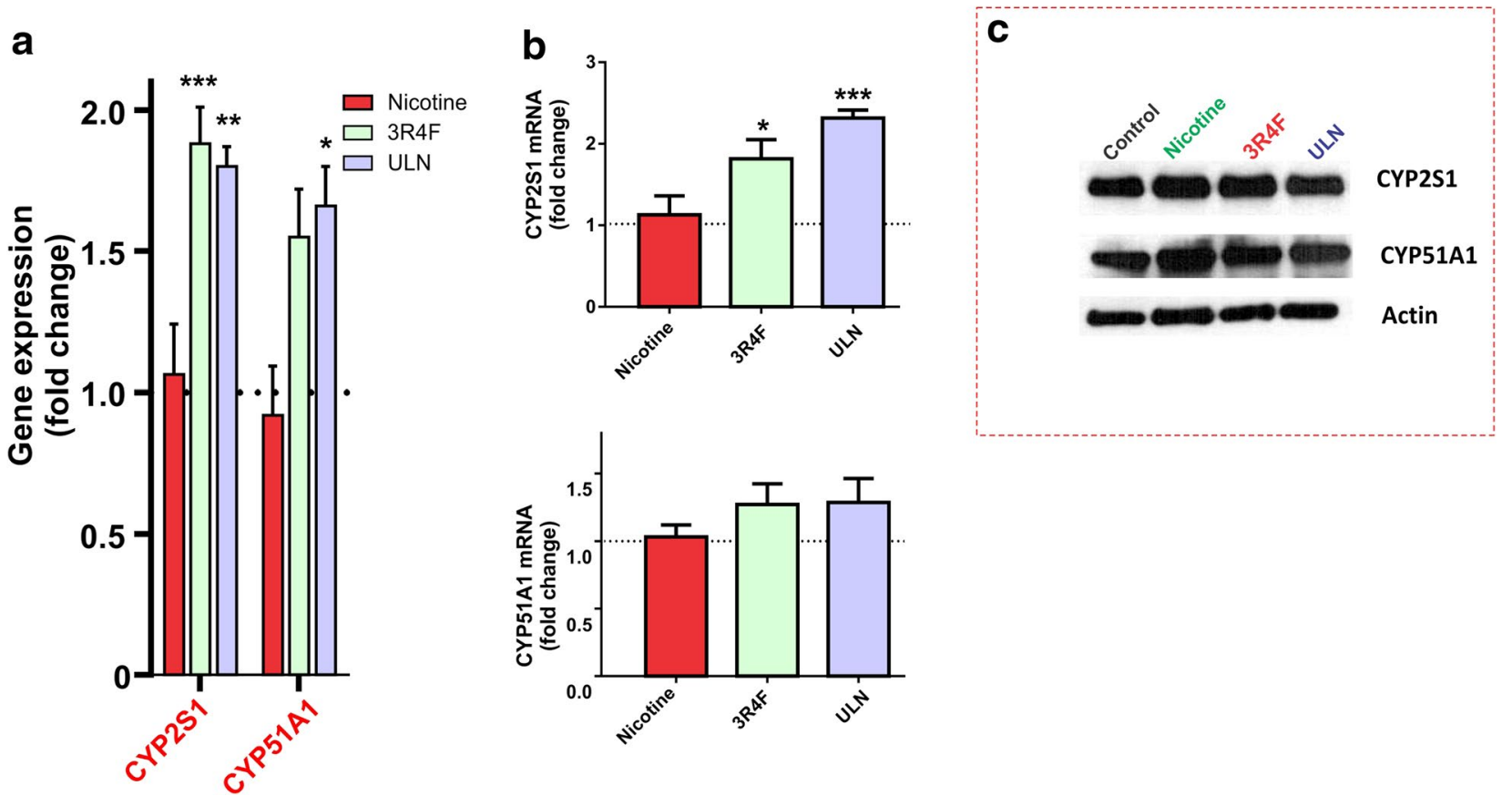

Figure 3 Effects of CSE on Phase I cytochrome P450s detoxification genes. As mentioned earlier, hCMEC/D3 cell monolayers were exposed to nicotine $(100 \mathrm{ng} / \mathrm{mL})$ or CSE derived from 3R4F or ULN cigarettes. Following exposure for $24 \mathrm{~h}$, expression of CYPs-CYP2S1 and CYP51A1 was analyzed by a DNA microarray, b real time PCR for mRNA; and $\mathbf{c}$ protein expression was analyzed by western blotting. Representative western blots were shown with actin as a loading control; data were expressed as mean \pm SEM (fold change over control). ${ }^{*} p<0.05,{ }^{* *} p<0.01$, ${ }^{* * *} p<0.001$ vs. control. $\mathrm{n}=6$ biological replicates/condition.

\section{CSE alters the efflux activity but not the expression of BBB P-glycoprotein}

Blood brain barrier endothelial cells are highly enriched with polarized expression of ATP-binding cassette superfamily of drug efflux transporters such as P-glycoprotein (P-gp) that prevent the brain penetration and accumulation of toxic substances including xenobiotics. Previous studies have shown that Nrf2 activation induces the transcription of major drug efflux transporters [11]. As shown in Figure 4, microarray analysis revealed a significant up-regulation of two major ABC efflux transporters, P-glycoprotein (P-gp; ABCB1) and multidrug resistant protein-4 (MRP-4; ABCC4; $\mathrm{p}<0.05$, vs. control) in response to $3 \mathrm{R} 4 \mathrm{~F}$ exposure. The biological effect is consistent with a marked increase in rhodamine123 efflux ( $\mathrm{p}<0.05$, vs. control) used as a measure of P-gp functional activity. CSE from ULN also increased the gene expression of P-gp ( $p<0.01$ vs. control), but not that of MRP4 (Figure 4b). However, RT-PCR and western blotting analysis of the cellular membrane fractions did not show a corresponding increase in gene transcription and/ or protein expression levels for either of these transporters (Figure 4c). Interestingly, when compared to nicotine, TS did produce a statistically significant increase of P-gp transcription when compared to nicotine since surprisingly nicotine caused a modest reduction in P-gp transcription when compared to controls.

\section{CSE potentiates synthesis and activity of various antioxidants in BBB endothelial cells}

The next major component of the Nrf2-ARE pathway is the anti-oxidant system. In this study, we compared the effects of CSE derived from conventional and reduced exposure products on the genes involved in synthesis of major anti-oxidant glutathione (GSH), such as glutathione cysteine ligase and SLC7A11 [20]. Genome wide transcriptional profiling revealed an amplified gene expression of GCL-modifier unit (GCLM) and SLC7A11 in $\mathrm{BBB}$ endothelial cells exposed to CSE from 3R4F and ULN (Figure 5a). These results were further validated by RT-PCR analysis indicating a potential up-regulation of SLC7A11 (Figure 5b, $\mathrm{p}<0.05$ and $\mathrm{p}<0.01$ vs. control) and GCLM transcription (Figure 5c, p $<0.05$ vs. control) by 3 R4F and ULN smoke extracts, respectively. Moreover, alterations in the protein expression of SLC7A11 and GCLM followed a similar trend with significant increase upon exposure to CSE derived from both products (Figure $5 \mathrm{~b}, \mathrm{c}$ ). In addition, 3R4F but not ULN moderately 

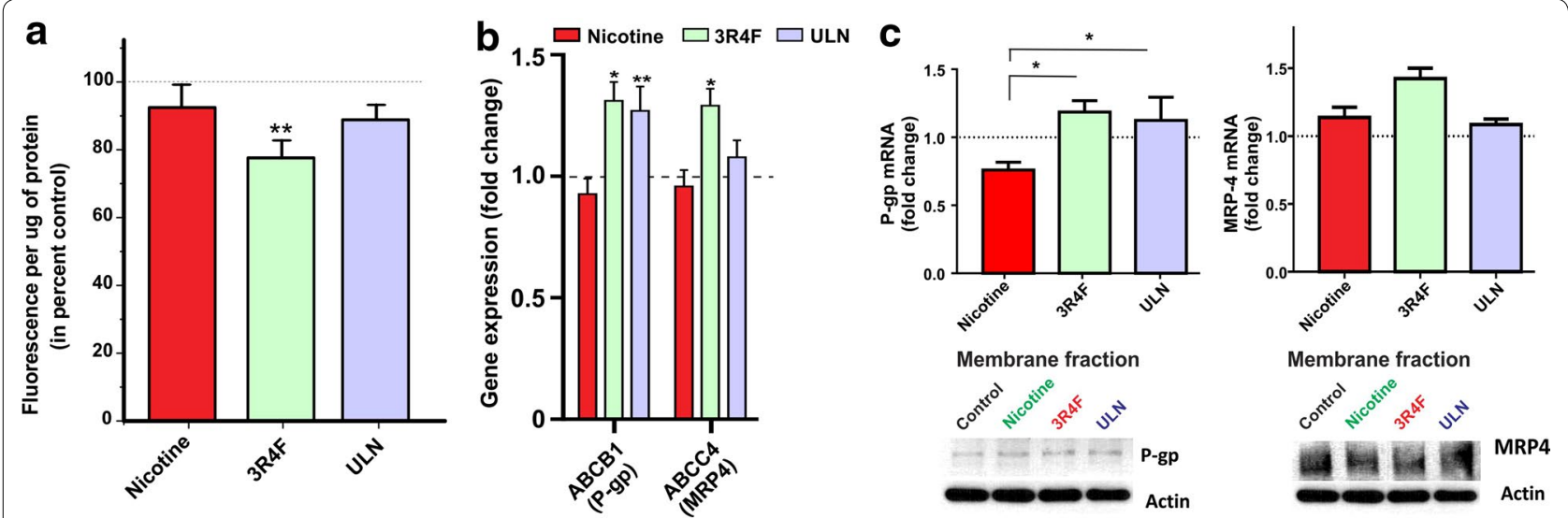

Figure 4 Effects of CSE on ABC efflux transporter expression and functionality in hCMEC/D3 cell line. Cells were exposed to nicotine (100 ng/mL) or CSE derived from 3R4F or ULN cigarettes. a P-gp efflux activity was determined by intracellular accumulation of rhodamine123 (a P-gp substrate) efflux, as an indirect correlate of P-gp activity $n=3 /$ condition and replicated twice. $\mathbf{b}$ Transcriptome analysis of $A B C$ efflux transporters, $A B C B 1$ (P-gp) and ABCC4 (MRP4) following treatment ( $n=6$ biological replicates); $\mathbf{c}$ RT-PCR analysis of mRNA expression of P-gp and ABCC4 in hCMEC/D3 cells ( $n=6$ biological replicates); western blot analysis of transporter protein expression ( $n=6$ biological replicates). Representative western blots were shown with actin as a loading control. Data were expressed as mean \pm SEM (fold change over control). ${ }^{*} p<0.05,{ }^{* *} p<0.01$, vs. control.

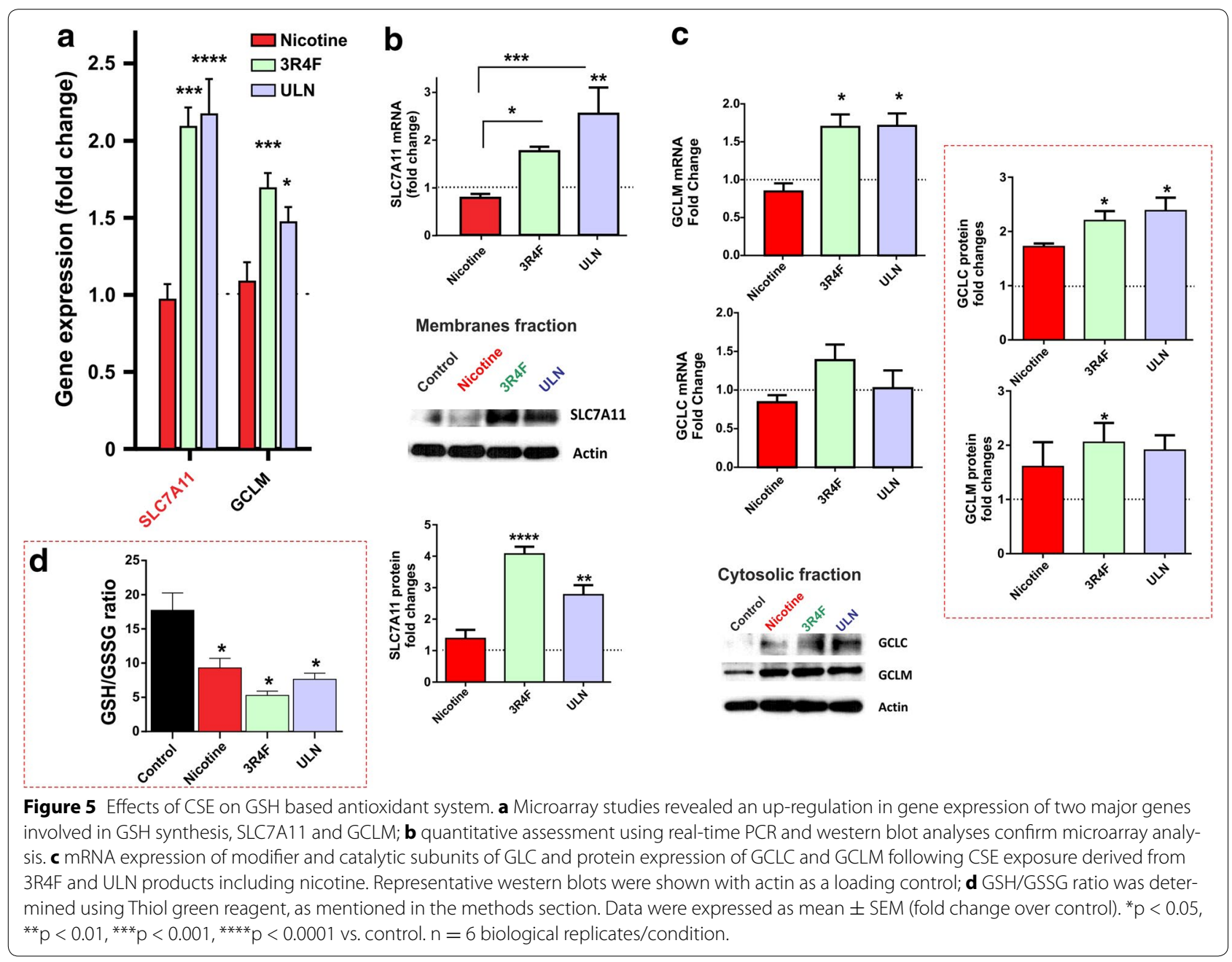




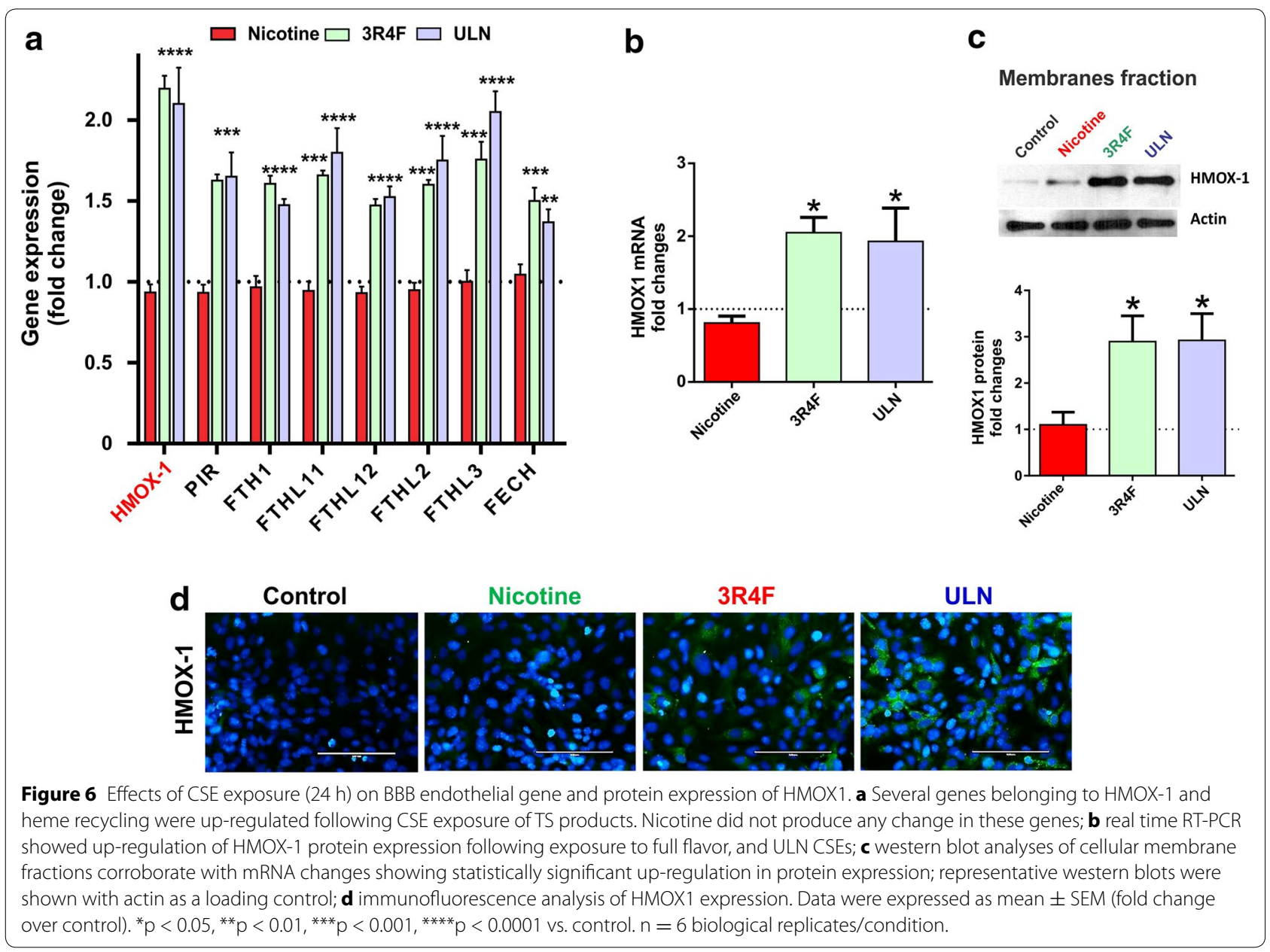

increased gene transcription of GCL-catalytic subunit (GCLC), while GCLC protein expression was up-regulated by both products to a similar extent (Figure 5c). By contrast, nicotine did not produced any significant alterations in GCLM and SLC7A11 gene expression, although we observed a marked increase in the cytoplasmic expression of the catalytic and modifier subunits of GCL following nicotine exposure, as shown by western blotting (Figure 5c). Importantly, all the tested products (including nicotine) reduced the turn-over rate of cellular GSH, as demonstrated by the GSH/GSSG ratio (Figure $5 \mathrm{~d}, \mathrm{p}<0.05$ ). This clearly suggests a depletion of cellular antioxidant protection against incumbent oxidative stress load caused by the exposure to smoke extracts and nicotine (in smaller measure).

Continuing on the same path, we assessed the effects of nicotine, 3R4F and ULN exposure on gene expression, transcription and translation of heme oxygenase (HMOX-1). HMOX-1 is also a component of the cellular antioxidant cytoprotective mechanisms along with other molecular networks (including ferritin and pirin involved in iron/metal sequestration) [21]. As shown in Figure 6a, transcriptome analysis revealed a significant increase in the gene expression levels of HMOX-1 and other antioxidant molecules in response to 3R4F and ULN exposure. Results were corroborated by RT-PCR and western blot analyses in line with gene expression data as shown in Figure 6b, c respectively ( $\mathrm{p}<0.05$, vs. control). Immunofluorescence analysis of the BBB endothelial monolayers further supports these observations (Figure 6d).

\section{CSE increases NF- $\kappa \beta$ expression and nuclear translocation}

We next determined the impact of TS and nicotine on

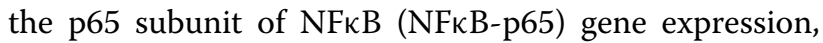
a transcriptional factor and potential activator of oxidative and inflammatory stress pathways [22]. As shown in Figure 7a1, the mRNA expression of NFкB-p65 was markedly elevated by CSE exposure of both products with ULN producing a stronger response in 3R4F. We also observed a significant increase in the activation and nuclear translocation of NFKB-p65 following exposure to either 3R4F or ULN smoke extracts (Figure 7a2). 


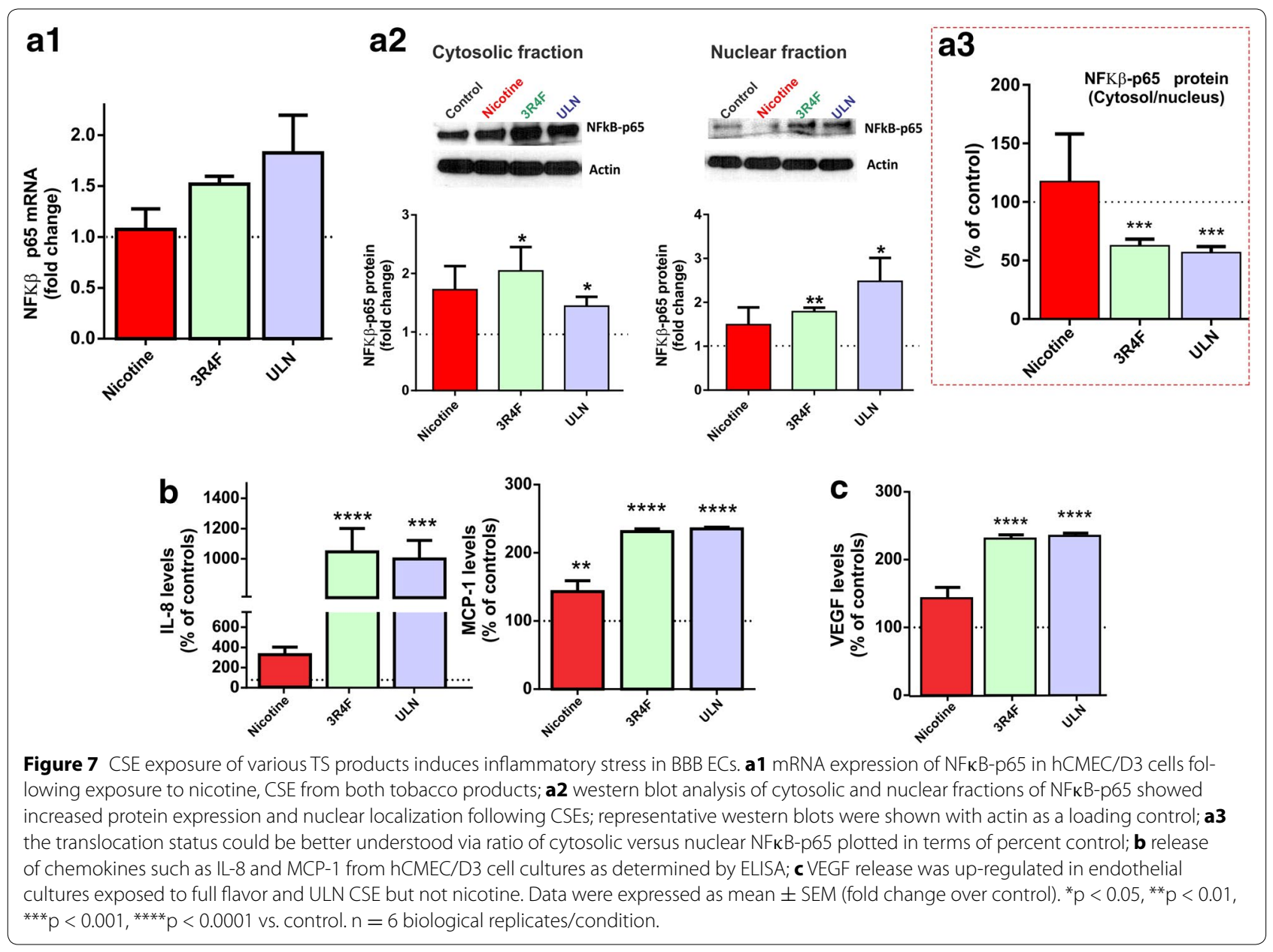

As shown in Figure 7a3, the cytoplasm/nuclear ratio of NFкB-p65 in BBB endothelial cultures exposed to 3R4F or ULN smoke extracts was only $50 \%$ of that measured in controls. By contrast, nicotine exposure alone did altered neither the mRNA expression nor the nuclear translocation of NFкB-p65 (Figure 7a1-a3).

Secretion of the pro-inflammatory cytokine interleukin 8 (IL-8) and the chemokine Monocyte Chemoattractant Protein-1 (MCP-1) are in agreement with NFкB-p65 activation (Figure $7 \mathrm{~b}$ ). Both CSE from 3R4F and ULN cigarette products amplified the IL- 8 secretory response by tenfold compared to control cultures (Figure $7 \mathrm{~b}$, $\mathrm{p}<0.0001)$. Nicotine $(100 \mathrm{ng} / \mathrm{mL})$ was also found to significantly elevate the release of IL- 8 from BBB endothelial cells $(>2$-fold), although the magnitude of nicotine's effects was relatively very low when compared to CSEs (Figure $7 \mathrm{~b}$ ). In addition, release of vascular endothelial growth factor (VEGF), a known modulator of vascular angiogenesis, was also significantly increased in response to the exposure to $3 \mathrm{R} 4 \mathrm{~F}$ and ULN-derived CSE (Figure $7 \mathrm{c}, \mathrm{p}<0.0001)$. Nicotine treatment alone was also found to induce the endothelial secretion of MCP-1 and VEGF by a marginal 1.5 fold over control (Figure 7b, c).

\section{Discussion}

The role of Nrf2 dependent antioxidant response pathway is well established in disorders aggravated by cigarette smoke such as lung emphysema, COPD, atherosclerosis and cardiac dysfunction [23-25]. In these disorders Nrf2 deficiency has clearly been demonstrated to increase the susceptibility to cellular toxicity [26] and several natural and/or synthetic antioxidant based supplemental therapies have proven to be beneficial in ameliorating the oxidative damage $[27,28]$.

In this study we assessed the activity and biological responses of the human $\mathrm{BBB}$ endothelium to a number of biological factors related to Nrf2 activation. The endpoint goal of this work was to unravel (at a molecular level) the cause-effect relationship between the oxidative potential of full flavor (3R4F) and "reduced exposure" (ULN) tobacco products and the biological response of these cells. 
As expected the biological response of the $\mathrm{BBB}$ endothelium in respect to Nrf2 expression/activity supported our original hypothesis of a direct correlation between the oxidative potential of a tobacco product and its cellular toxicity. This is clearly shown in Figure $1 \mathrm{dem}-$ onstrating a striking relationship between oxidative stress generated by the CSE extracts on cultured endothelial cells (Figure 1a) and the effect on the expression level and nuclear translocation of Nrf2 in the same cells (Figure 1d). A data that already argue with the notion of "reduced exposure" tobacco product (such as ULN) being intrinsically less harmful than conventional cigarettes (such as 3R4F). Our results also indicate that cigarette reduction in nicotine content has a negligible or at best a very modest effect on the overall "safety" of the product itself in terms of oxidative damage to cells and tissues.

Nrf2-dependent anti-oxidant response is mainly divided into detoxification enzymes (such as Phase Ioxidation/reduction, Phase II-conjugation enzymes and Phase III-efflux transporters) and anti-oxidant based system (such as glutathione and thioredoxin) [11]. As a follow up study, we performed transcriptome analysis to screen for the expression of several downstream targets of Nrf2-dependent antioxidant response. Nrf2 dependent downstream genes were also highly up-regulated in response to CSE exposure whereas nicotine did not bear any significant effect. Specifically, a number of Phase I detoxification genes depending upon Nrf2/ARE pathway activation were up-regulated including NQO1 (see also Additional file 1: Table S1). NQO1 is a cytoplasmic 2-electron reductase that prevents the reduction of quinones and the resulting production of radical species. NQO1 response to CSE exposure was observed at the gene expression, transcription and protein expression levels (see Figure 2). Taken together, we show that the both conventional and "reduced exposure" tobacco products (but not nicotine) elicit a strong oxidative stress response in $\mathrm{BBB}$ endothelial cells that well correlate with Nrf2 activation also elicited by CSE exposure.

Expression of Phase I Cytochrome P450s genes such as CYP2S1 and CYP51A1 were also up-regulated by exposure to CSE from both cigarette products although a corresponding increase in protein expression was not evident (see Figure 3 ). This could be possibly due to a longer time requirement for the gene expression changes to translate into measurable alteration of protein expression. Important to note however, is that very few studies have reported strong baseline expression of CYPs in normal BBB endothelium [29]. Thus, a distinct pattern of gene up-regulation of both CYP2S1 and CYP51A1 which have been observed in response to TS detoxification is a relevant piece of information further supporting the involvement of Nrf2 -dependent cytoprotection in response to TS exposure (see also Additional file 1: Table S2).

Another important component of $\mathrm{BBB}$ is the class of $\mathrm{ABC}$ transporters that function to efflux out both endogenous and exogenous toxicants out of the brain. As shown in Figure 4a, our data provides novel evidence of a potential augmentation of two classical ABCs, ABCA1 (P-gp) and $\mathrm{ABCC}$ (MRP4) at the $\mathrm{BBB}$ in response to CSE exposure. These changes were tangible enough to show at the gene expression level however were too small to be detected to a significant level of confidence at the transcription and translation level. Nevertheless functional assessment of an assessment of functional efflux activity specifically for P-gp (measured via Rhodamine-123; see also Figure 4c) clearly demonstrated statistically significant higher efflux function in EC cultures exposed to 3R4F. ULN effect was more modest. Considering that nicotine mildly down-regulated P-gp gene expression and did not affect its efflux activity, the difference between 3R4F and ULN in respect to P-gp activity can possibly reflect a difference in cigarette composition and substances released in solution which may differently affect P-gp expression. This provided a reasonable explanation (although difficult to ascertain given the complexity of cigarette composition) where again the total oxidative capacity of the TS product was the determining factor of cellular toxicity and activation of cytoprotective mechanisms. In addition to these major drug efflux transporters, gene array screening revealed up-regulation of several other $\mathrm{ABC}$ transporters primarily involved in cholesterol trafficking across the BBB (See also Additional file 1: Table S3).

The next level of cytoprotection provided by Nrf2-ARE pathway is the heightened synthesis of anti-oxidants such as GSH, thioredoxin. Exposure to CSE from 3R4F and ULN both elicited gene transcription and increase in the protein expression levels of the Cystine/glutamate transporter antiporter SLC7A11 and the Glutamate cysteine ligase regulatory subunit (also known as gamma-glutamyl cysteine synthetase) which is the first rate limiting enzyme of glutathione (GSH) synthesis (Figure $5 \mathrm{a}-\mathrm{c}$ ). Note, in fact, how the GSH//GSSG rate reflects the level of oxidative stress caused by TS exposure leading to GSH depletion (most evident in BBB endothelial cultures exposed to 3R4F; see Figure 5d). Note also the nicotine is capable in some measure to elicit oxidative stress. This is also reflected in the more modest but still significant decrease of GSH/GSSG ratio observed in BBB endothelial cells exposed to nicotine. Although the effect is relatively modest, this can explain while 3R4F exposure determined the most significant impact in terms of GSH reduction when compared to ULN product. ULN contain similar amount of TAR but negligible amount of nicotine. 
In addition, concomitant up-regulation of several other genes related to NAPDH production were also observed. (See Additional file 1: Table S4). These genes function to recycle and regenerate the anti-oxidants back to the inactive state [11].

Oxidative and inflammatory changes following TS exposure have been reported to elevate stress inducible enzyme HMOX-1 [30, 31]. Both 3R4F and ULN products showed comparable alterations in HMOX-1 (see Figure 6) and related genes (such as pirin, ferritin). Interestingly, apart from metal chelation; pirin is also reported to govern the activation of $\mathrm{NF \kappa} \beta$ and its related genes via Nrf2 [21]. It is a non heme Fe protein that may function to sense redox stress for the NFк $\beta$ pro-inflammatory signalling and govern the expression of downstream genes involved in immune responses [21, 32, 33]. Ferritin instead is a major intracellular storage protein which helps with iron homeostasis. It is usually composed of various ratios of light chain and heavy chain subunits. Following CSE treatment we observed increased transcription of several of these subunits whereas, both 3R4F and ULN products led to the activation of genes related to iron sequestration. In contrast, nicotine failed to induce any changes in gene and/or protein expression of HMOX-1. This again reiterated that the level of BBB toxicity was dependent on the oxidative and/or inflammatory capacity of the TS product which may not be discriminated by the nicotine content alone.

Apart from Nrf2, another cell survival transcription factor reported in event of oxidative stress is nuclear factor kappa-light-chain-enhancer of activated B cells (NF$\kappa B)$; a protein complex that controls DNA transcription and is involved in cellular responses to harmful stimuli (including free radicals, pro-inflammatory cytokines, ultraviolet irradiation, etc.) and plays a key role in regulating the immune and cell survival [22]. NFкB-p65 not only increased in total cytosolic levels, but also showed increased translocation into the nucleus (See Figure 7) in response to CSE exposure. Apart from classical activation of NFK $\beta$ in events of inflammatory/oxidative stress, Nrf1/ Nrf2 can up-regulate GCLC transcription indirectly via modulation of levels of NFK $\beta[34,35]$. Although based on current results we cannot assertively state if NFкB-p65 was directly or indirectly activated; we observed a significant increase of its nuclear translocation following CSE exposure. The effect was particularly enhanced in response to ULN-derived CSE; a cigarette product considered "reduced exposure" and less harmful than conventional products. In addition, NFк $\beta$-p65 expression and translocation patterns consistently paralleled stress fighting responses as reported in earlier observations. NFк $\beta$ activation typically involves either canonical or non-canonical pathways. The selection dependents on whether p50/p65 (RelA) (canonical) or p52/RelB (noncanonical) is involved in the translocation and downstream activation. We could clearly observe increased translocation of the p65 sub unit into the nucleus indicating activation of the canonical pathway and associated pro-inflammatory/cell survival responses. At this point, it is difficult assert if only this pathway was associated with the TS toxicity coping mechanisms; further studies will be required in future to specifically address this conundrum. Furthermore, we observed an increase of IL-8 release following both 3R4F and ULN-derived CSE exposures. In agreement with our findings, p65 sub unit was reported to activate IL-8 expression via promoter binding [36].

Interestingly, previous in vitro studies by Barr et al. [37] have shown a dose dependent nicotine-induced activation of stress-dependent NFkB pathway in mesencephalic cells. However, we observed only a marginal response to nicotine exposure (including NFк $\beta$-p65 protein expression and nuclear translocation). A possible explanation of this discrepancy could be attributed to two factors: (1) for our experiments the reference concentration of nicotine used was approximately $0.6 \mu \mathrm{M}$ which falls to the lower end of the concentrations tested by Barr and co-workers; (2) time of assessment. In our study, oxidative stress measurements (as shown in Figure 1) were measured at $3 \mathrm{~h}$ at which point we did note a slight increase of oxidative stress in nicotine-exposed cultures versus controls. However, measurements of downstream effects such as NFkB-p65 activation (expression and nuclear translocation) were assessed at $24 \mathrm{~h}$ post exposure. It is possible that the oxidative stress effects elicited by nicotine fade off and became negligible at that time point.

As a part of vascular inflammation; cigarette-toxicity can lead to the up-regulation of several chemokines that promote cellular adhesion of white blood cells and facilitate their extravasation across the brain vasculature [38]. To understand the extent of vascular inflammation produced in the ECs following CSE exposure; we measured two major chemokines (IL-8 and MCP-1). Both these chemokines have been reported to be involved in the chemotaxis of neutrophils and monocytes after cigarette smoke exposure in lung and other peripheral vasculatures [39-41]. Release of IL-8 and MCP-1 was significantly increased in $\mathrm{BBB}$ endothelial cultures exposed to CSE (both 3R4F and ULN). This is in agreement with earlier published results by our group demonstrating a number of inflammatory changes (including IL-6 release and up-regulation of vascular adhesion molecules such as VCAM-1, Pecam-1) in BBB ECs exposed to TS [8]. Finally, CSE from both 3R4F and ULN elicited 
endothelial release of VEGF, a known modulator of vascular angiogenesis released in response to hypoxic condition and implicated in the alteration of BBB vascular integrity $[42,43]$.

\section{Conclusion}

In summary, this novel study provides a detailed understanding of Nrf2- related cytoprotective mechanisms activated in response to TS exposure and effectively correlate them with their oxidative and inflammatory potential. Whole soluble components present in CSE and not nicotine seems to be the primary determinant of vascular toxicity. However, the identity of these specific compounds remains still elusive. Given the extremely large number of compounds contained in cigarette smoke, the identification of the specific toxicant(s) (not necessarily related to cancer genesis) responsible for the effects noted above (including potential synergistic and additive interactions) will be extraordinarily difficult to assess. In respect to our results as well as previous studies by our group and others, it is plausible that the oxidative stress stimuli generated by chronic TS exposure can effectively overwhelm the Nrf2 and NFк $\beta$-dependent cytoprotective endothelial mechanisms. This can ultimately lead to impairment of $\mathrm{BBB}$ function and integrity thus promoting cerebrovascular and CNS disorders. It is in fact well known that (1) chronic smokers suffer from antioxidant shortage (e.g., vitamin $\mathrm{C}$ and $\mathrm{E}$ ) caused by increased antioxidative mobilization in response to systemic oxidative stress evoked by ROS-enriched TS [44, 45]; (2) antioxidant supplementation reduces the TS-dependent oxidation and inflammation in animals and cells $[10,46]$; (3) cigarette smoking facilitate the development of a proatherosclerotic environment by inducing inflammation (recruitment of leukocytes through cytokine signaling [38-41, 47] and oxidation of low-density lipoprotein cholesterol $[7,48]$. Additional in vivo studies using direct inhalation models will be necessary to reveal the extent of the damage and risks associated with chronic tobacco smoking at the cerebrovascular level.

\section{Methods}

\section{Materials and reagents}

The antibodies used in this study were obtained from the following sources: Rabbit Nrf2 (\#ab62352) from Abcam; rabbit MRP-4 (\#12705S), mouse NQO1 (\#3187), rabbit SLC7A11\#12691, rabbit HMOX-1 \#5061, NFkb p65 \#8242 from Cell Signaling Technology (Danvers, MA, USA); mouse GCLC \#WH0002729M1, mouse GCLM \#WH0002730M, rabbit CYP2S1 \#SAB4501343, rabbit CYP51A1 (\#C8873), $\beta$-actin \#A5441 from Sigma-Aldrich (St. Louis, MO, USA); Mouse P-gp from Calbiochem (\#517310); donkey anti-rabbit (\#NA934) and sheep anti-mouse (\#NA931) HRP-linked secondary antibodies from GE Healthcare (Piscataway, NJ, USA); mouse anti-claudin 5 (\#35-2500), goat anti-rabbit (\#A11008) and anti-mouse (\#A21422) conjugated to Alexa Fluor 488 and 555 from Invitrogen (Camarillo, CA, USA). Sterile culture ware was obtained from Fisher Scientific (Pittsburgh, PA, USA), while other reagents and chemicals were purchased from Sigma-Aldrich (St. Louis, MO, USA) or Bio-rad laboratories (Hercules, CA, USA).

\section{TS preparation}

We followed a standardized ISO/FTC standard smoking protocol $(35 \mathrm{~mL}$ draw, $2 \mathrm{~s}$ puff duration, 1 puff per 60 s), using a Single Cigarette Smoking Machine (SCSM, $\mathrm{CH}$ Technologies Inc., Westwood, NJ, USA) to prepare our cigarette smoke extracts (CSE) as previously detailed elsewhere [8]. 8 puffs per cigarette were bubbled directly into phosphate buffered saline (PBS). Three cigarettes per preparation were used to make $3 \times$ concentration (or 300\%) stock solution which was then diluted to the desired concentration. Two types of cigarettes were used for this study: (a) full flavor cigarettes (3R4F, University of Kentucky) equivalent to conventional full flavor brands containing $9.4 \mathrm{mg}$ tar and $0.726 \mathrm{mg}$ nicotine per cigarette; (b) ultralow nicotine Spectrum cigarettes (from NIH/NIDA) equivalent to ultralow nicotine brands containing $0.03 \mathrm{mg}$ nicotine and $9 \mathrm{mg}$ tar per cigarette. Tar content of these cigarettes is similar to that of 3R4F (full flavor product) but that of nicotine is negligible.

\section{Cell culture}

The hCMEC/D3 cells donated by Dr. Couraud (INSERM, Paris) (passage 29-30) were seeded on collagen coated cell culture flasks $\left(2.0 \times 10^{4} / \mathrm{cm}^{2}\right)$ and maintained at $37^{\circ} \mathrm{C}$ with $5 \% \mathrm{CO}_{2}$ in EBM-2 basal medium (Lonza, Walkersville, MD, USA) supplemented with 5\% FBS (Atlanta Biologicals, Lawrenceville, GA, USA), Fibroblast Growth Factor (Sigma Aldrich Inc), chemically defined lipid concentrate (Life Technologies, Carlsbad, CA, USA), antibiotic/antimycotic (1:1, Atlanta Biologicals, GA, USA and HEPES $(10 \mathrm{mM})$. Medium was changed once after 2 days and then every other day until cells formed a continuous confluent monolayer. BBB endothelial monolayers were then chronically exposed ( 3 times/ $24 \mathrm{~h}$ ) to a final 5\% CSE concentration [8] derived from freshly prepared smoke extracts diluted in EBM-2 culture media. Following CSE exposure cells were processed for RNA and protein collection. Please note that a 5\% CSE final concentration (using 3R4F cigarettes as reference) yields a nicotine output of $\approx 100 \mathrm{ng} / \mathrm{mL}$, which is comparable to the steady state blood nicotine concentration measured in an average chronic smoker $(\approx 20$ cigarettes/day) [8, 49-51]. Experiments related to nicotine exposure as a standalone 
agent where performed by directly diluting nicotine in the culture media at the desired concentration $(100 \mathrm{ng} /$ $\mathrm{mL})$.

\section{Microarray analysis}

Total RNA was extracted using RNAeasy kit (Qiagen \#74104) according to manufacturer's instructions. The RNA concentration and purity was determined using Nanodrop ND-1000, before sending the samples Boston Children's Hospital for further microarray analysis. A total of $100 \mathrm{ng}$ of RNA was required for the hybridization along with appropriate quality control (QC) samples. Illumina Human HT-12 expression bead chip was utilized for the hybridization of samples on the chip (a total of 12 samples per chip). Raw data in the form of signal intensities for each gene probe were screened, filtered and converted into fold change values over control.

\section{Real-time PCR}

RNeasy mini kit (Qiagen Inc, \#74104) was used for the extraction of total RNA from BBB endothelial cell cultures. Briefly, cells were lysed using RLT buffer and homogenized using a QIA shredder. The total RNA was then extracted from the lysate as per the manufacturer's guidelines. Further, samples were analyzed by Nanodrop ND-1000 for quantity and purity (260/280 ratio close to 1.9-2.1). A $20-\mu \mathrm{L}$ first-strand cDNA synthesis reaction was performed using SuperScript III (Life Technologies, carlsbad, CA) and $5 \mu \mathrm{g}$ of total RNA. $1 \mu \mathrm{L}$ of resulting cDNA was used in a PCR reaction of $25 \mu \mathrm{L}$ containing $2 \mu \mathrm{L}$ of each primer $(10 \mu \mathrm{M})$. Primer pairs used in amplification have been detailed out in Additional file 1: Table S5. Amplification was performed using a Bio-Rad CFX96 Touch $^{\text {Ti }}$ Real-Time PCR detection system. The relative expression changes of the target genes i was then determined by $\Delta \Delta \mathrm{Ct}$ method [52], wherein target gene expression (based on $\mathrm{Ct}$ ) was normalized against the house keeping gene ( $\beta$-actin).

\section{Western blotting}

Proteins was collected and fractionated using Subcellular Protein Fractionation Kit for cultured cells (Thermo scientific, \#78840) according to the manufacturer's guidelines. Protein was quantified using Pierce BCA Protein Assay Kit (Thermo Scientific, \#23225) and then denatured at $95^{\circ} \mathrm{C}$ for 5 min using sample buffer. Denatured samples $(15-20 \mu \mathrm{g})$ were subjected to SDS-PAGE (4-15\% gradient gel) and then transferred to PVDF membranes $(2 \mathrm{~h}$ transfer at $100 \mathrm{~V})$ for further blotting. These PVDF membranes were blocked for $2 \mathrm{~h}$ using $5 \%$ non-fat dry milk in Tris buffered saline (TBS) containing $0.1 \%$ Tween-20 (TTBS) and subsequently incubated overnight with mouse $(1: 500)$ or rabbit $(1: 1,000)$ primary antibodies. This was followed by four TTBS washes (10 min each) and subsequent incubation with anti-rabbit or anti-mouse $(1: 10,000)$ HRP-conjugated secondary antibodies for $2 \mathrm{~h}$. After four TTBS washes of $10 \mathrm{~min}$ each, the blots were developed using chemiluminescence detection method (using X-ray film based autoradiography). Membranes were subsequently stripped and probed for other proteins. Ms $\beta$-actin $(1: 10,000)$ was used as a loading control. Band densities were analyzed by Licor Software, normalized to actin and expressed as fold change over control protein expression.

\section{Immunofluorescence analysis}

Cells were cultured in a two-well chamber slides for IFC analysis. Cells were fixed with $4 \%$ formaldehyde (15 min at $4^{\circ} \mathrm{C}$ ) after period of $24 \mathrm{~h}$. The slides were then washed with PBS, 5 min each for a total of three washes. This was followed by blocking with $5 \%$ goat serum (SigmaAldrich, St. Louis, MO, USA) in PBS at room temperature for $50 \mathrm{~min}$. Fixed cells were then incubated with primary antibodies (prepared in 5\% GSA in PBS) at $4^{\circ} \mathrm{C}$ overnight. After PBS washes, cells were incubated for $1 \mathrm{~h}$ at RT with Alexa Fluor 488 conjugated goat anti-rabbit or Alexa Fluor 555 conjugated goat anti-mouse secondary (1:1000) antibodies. After three washes with PBS (of 5 min each), cells were rinsed, air dried and mounted with DAPI in Prolonged Gold Anti-fade mounting media (Invitrogen, OR, USA). They were left for overnight drying in the dark before imaging with EVOS digital inverted fluorescence microscope. Cells stained with secondary antibodies alone were used as negative controls.

\section{GSH/GSSG analysis}

GSH/GSSG ratio in BBB endothelial cell cultures was determined using GSH/GSSG Ratio Detection Assay Kit (Fluorometric-Green) (Abcam Inc. \#ab138881) according to the manufacturer's guidelines. The samples were prepared by lysis of total cell protein in T-PER lysis buffer followed by a dilution of 1:50 for GSH analysis. In brief, serial dilution of GSH and GSSG stock standards were prepared along with assay mixtures for detection of GSH and total GSH using 100 $\times$ Thiol green stock solutions, assay buffer and GSSG probe. A one- step fluorimetric reaction of sample with respective assay buffers were incubated for $30 \mathrm{~min}$. Fluorescence intensity was then monitored at Ex/Em of 490/520 nm. GSSG was determined by subtracting GSH from total GSH. Finally ratio of GSH was plotted against GSSG to obtain the GSH activity.

\section{Statistical analyses}

Data from microarray as well as proteomic studies were expressed as fold changes over control \pm standard error 
of mean (SEM). The data from all four groups were analyzed by $t$ test or one-way ANOVA using GraphPad Prism Software Inc. (La Jolla, CA, USA). Post hoc multiple comparisons were conducted using Tukey's test. P values $\leq 0.05$ were considered statistically significant.

\section{Additional file}

Additional file 1: Please refer to SI for primer sequences used for qRTPCR and additional tables related to gene expression studies.

\begin{abstract}
Authors' contributions
PN conceived the study and performed the experiments and drafted the manuscript. RKS helped drafting the manuscript. SP assisted in immunofluorescence studies and manuscript revision. LC supervised the project, performed data analysis and provided guidance during manuscript preparation and revisions. All authors read and approved the final manuscript.
\end{abstract}

\section{Author details}

${ }^{1}$ Department of Pharmaceutical Sciences, School of Pharmacy, Texas Tech University Health Sciences Center, 1300 S. Coulter Street, Amarillo, TX 79106, USA. ${ }^{2}$ Center for Blood Brain Barrier Research, Texas Tech University Health Sciences Center, Amarillo, TX 79106, USA.

\section{Acknowledgements}

These studies were supported by NIH/NIDA R01-DA029121-01A1 and in part by A.R.D.F to Dr. Luca Cucullo. Gene Array analyses were performed by the Molecular Genetics Core Facility at Children's Hospital, Boston supported by $\mathrm{NIH}-\mathrm{P} 50-\mathrm{NS} 40828$ and NIH-P30-HD18655.

\section{Compliance with ethical guidelines}

\section{Competing interests}

The authors declare that they have no competing interests.

Received: 16 March 2015 Accepted: 3 June 2015

Published online: 23 June 2015

\section{References}

1. (2008) Smoking-attributable mortality, years of potential life lost, and productivity losses_-United States, 2000-2004. MMWR Morb Mortal Wkly Rep 57: 1226-1228

2. (2013) WHO report on the global tobacco epidemiC. Ref Type: Generic

3. Hernan MA, Olek MJ, Ascherio A (2001) Cigarette smoking and incidence of multiple sclerosis. Am J Epidemiol 154:69-74

4. Mannami T, Iso H, Baba S, Sasaki S, Okada K, Konishi M et al (2004) Cigarette smoking and risk of stroke and its subtypes among middleaged Japanese men and women: the JPHC Study Cohort I. Stroke 35:1248-1253

5. Rusanen M, Kivipelto M, Quesenberry CP Jr, Zhou J, Whitmer RA (2011) Heavy smoking in midlife and long-term risk of Alzheimer disease and vascular dementia. Arch Intern Med 171:333-339

6. Zuo L, He F, Sergakis GG, Koozehchian MS, Stimpfl JN, Rong Y et al (2014) Interrelated role of cigarette smoking, oxidative stress, and immune response in COPD and corresponding treatments. Am J Physiol Lung Cell Mol Physiol 307:L205-L218

7. Messner B, Bernhard D (2014) Smoking and cardiovascular disease: mechanisms of endothelial dysfunction and early atherogenesis. Arterioscler Thromb Vasc Biol 34:509-515

8. Naik P, Fofaria N, Prasad S, Sajja RK, Weksler B, Couraud PO et al (2014) Oxidative and pro-inflammatory impact of regular and denicotinized cigarettes on blood brain barrier endothelial cells: is smoking reduced or nicotine-free products really safe? BMC Neurosci 15:51
9. Sajja RK, Naik P, Cucullo L (2015) Differential cerebrovascular toxicity of various tobacco products: a regulatory perspective. J Pharmacovigil 3(1):1000e130

10. Hossain M, Mazzone P, Tierney W, Cucullo L (2011) In vitro assessment of tobacco smoke toxicity at the BBB: do antioxidant supplements have a protective role? BMC Neurosci 12:92

11. Ma Q (2013) Role of nrf2 in oxidative stress and toxicity. Annu Rev Pharmacol Toxicol 53:401-426

12. Pickett G, Seagrave J, Boggs S, Polzin G, Richter P, Tesfaigzi Y (2010) Effects of 10 cigarette smoke condensates on primary human airway epithelial cells by comparative gene and cytokine expression studies. Toxicol Sci 114:79-89

13. Boyle JO, Gumus ZH, Kacker A, Choksi VL, Bocker JM, Zhou XK et al (2010) Effects of cigarette smoke on the human oral mucosal transcriptome. Cancer Prev Res (Phila) 3:266-278

14. van Leeuwen DM, Gottschalk RW, van Herwijnen MH, Moonen EJ, Kleinjans JC, van Delft JH (2005) Differential gene expression in human peripheral blood mononuclear cells induced by cigarette smoke and its constituents. Toxicol Sci 86:200-210

15. Wright WR, Parzych K, Crawford D, Mein C, Mitchell JA, Paul-Clark M (2012) Inflammatory transcriptome profiling of human monocytes exposed acutely to cigarette smoke. PLoS ONE 7:e30120

16. Weksler B, Romero IA, Couraud PO (2013) The hCMEC/D3 cell line as a model of the human blood brain barrier. Fluids Barriers CNS 10:16

17. Hayes JD, Dinkova-Kostova AT (2014) The Nrf2 regulatory network provides an interface between redox and intermediary metabolism. Trends Biochem Sci 39:199-218

18. Johansson I, Ingelman-Sundberg M (2011) Genetic polymorphism and toxicology - with emphasis on cytochrome p450. Toxicol Sci 120:1-13

19. Thum T, Erpenbeck VJ, Moeller J, Hohlfeld JM, Krug N, Borlak J (2006) Expression of xenobiotic metabolizing enzymes in different lung compartments of smokers and nonsmokers. Environ Health Perspect 114:1655-1661

20. Rebrin I, Sohal RS (2008) Pro-oxidant shift in glutathione redox state during aging. Adv Drug Deliv Rev 60:1545-1552

21. Brzoska K, Stepkowski TM, Kruszewski M (2014) Basal PIR expression in HeLa cells is driven by NRF2 via evolutionary conserved antioxidant response element. Mol Cell Biochem 389:99-111

22. Bowie A, O'Neill LA (2000) Oxidative stress and nuclear factor-kappaB activation: a reassessment of the evidence in the light of recent discoveries. Biochem Pharmacol 59:13-23

23. Khanna A, Guo M, Mehra M, Royal W III (2013) Inflammation and oxidative stress induced by cigarette smoke in Lewis rat brains. J Neuroimmunol 254:69-75

24. Boutten A, Goven D, Artaud-Macari E, Boczkowski J, Bonay M (2011) NRF2 targeting: a promising therapeutic strategy in chronic obstructive pulmonary disease. Trends Mol Med 17:363-371

25. Mann GE, Niehueser-Saran J, Watson A, Gao L, Ishii T, de Winter P et al (2007) Nrf2/ARE regulated antioxidant gene expression in endothelial and smooth muscle cells in oxidative stress: implications for atherosclerosis and preeclampsia. Sheng Li Xue Bao 59:117-127

26. lizuka T, Ishii Y, Itoh K, Kiwamoto T, Kimura T, Matsuno Y et al (2005) Nrf2-deficient mice are highly susceptible to cigarette smoke-induced emphysema. Genes Cells 10:1113-1125

27. Guan SP, Tee W, Ng DS, Chan TK, Peh HY, Ho WE et al (2013) Andrographolide protects against cigarette smoke-induced oxidative lung injury via augmentation of Nrf2 activity. Br J Pharmacol 168:1707-1718

28. Sussan TE, Rangasamy T, Blake DJ, Malhotra D, El-Haddad H, Bedja D et al (2009) Targeting Nrf2 with the triterpenoid CDDO-imidazolide attenuates cigarette smoke-induced emphysema and cardiac dysfunction in mice. Proc Natl Acad Sci USA 106:250-255

29. Ghosh C, Gonzalez-Martinez J, Hossain M, Cucullo L, Fazio V, Janigro D et al (2010) Pattern of P450 expression at the human blood-brain barrier: Roles of epileptic condition and laminar flow. Epilepsia

30. Paine A, Eiz-Vesper B, Blasczyk R, Immenschuh S (2010) Signaling to heme oxygenase- 1 and its anti-inflammatory therapeutic potential. Biochem Pharmacol 80:1895-1903

31. Haines DD, Lekli I, Teissier P, Bak I, Tosaki A (2012) Role of haeme oxygenase-1 in resolution of oxidative stress-related pathologies: focus on cardiovascular, lung, neurological and kidney disorders. Acta Physiol (Oxf) 204:487-501 
32. Brzoska K, Stepkowski TM, Kruszewski M (2011) Putative proto-oncogene Pir expression is significantly up-regulated in the spleen and kidney of cytosolic superoxide dismutase-deficient mice. Redox Rep 16:129-133

33. Liu F, Rehmani I, Esaki S, Fu R, Chen L, de Serrano V et al (2013) Pirin is an iron-dependent redox regulator of NF-kappaB. Proc Natl Acad Sci USA 110:9722-9727

34. Yang H, Magilnick N, Ou X, Lu SC (2005) Tumour necrosis factor alpha induces co-ordinated activation of rat GSH synthetic enzymes via nuclear factor kappaB and activator protein-1. Biochem J 391:399-408

35. Yang H, Magilnick N, Lee C, Kalmaz D, Ou X, Chan JY et al (2005) Nrf1 and Nrf2 regulate rat glutamate-cysteine ligase catalytic subunit transcription indirectly via NF-kappaB and AP-1. Mol Cell Biol 25:5933-5946

36. Kunsch C, Lang RK, Rosen CA, Shannon MF (1994) Synergistic transcriptional activation of the IL-8 gene by NF-kappa B p65 (RelA) and NF-IL-6. J Immunol 153:153-164

37. Barr J, Sharma CS, Sarkar S, Wise K, Dong L, Periyakaruppan A et al (2007) Nicotine induces oxidative stress and activates nuclear transcription factor kappa B in rat mesencephalic cells. Mol Cell Biochem 297:93-99

38. Messner B, Bernhard D (2014) Smoking and cardiovascular disease: mechanisms of endothelial dysfunction and early atherogenesis. Arterioscler Thromb Vasc Biol 34:509-515

39. Giunzioni I, Bonomo A, Bishop E, Castiglioni S, Corsini A, Bellosta S (2014) Cigarette smoke condensate affects monocyte interaction with endothelium. Atherosclerosis 234:383-390

40. Lagente V, Planquois JM, Leclerc O, Schmidlin F, Bertrand CP (2008) Oxidative stress is an important component of airway inflammation in mice exposed to cigarette smoke or lipopolysaccharide. Clin Exp Pharmacol Physiol 35:601-605

41. Li JR, Zhou WX, Zhao ZX, Gao JM (2014) Differential expression of the inflammation-associated chemokines/cytokines in mouse lung after exposure to cigarette smoke and smoking cessation. Zhongguo Yi Xue Ke Xue Yuan Xue Bao 36:241-248

42. Fischer S, Wobben M, Marti HH, Renz D, Schaper W (2002) Hypoxiainduced hyperpermeability in brain microvessel endothelial cells involves VEGF-mediated changes in the expression of zonula occludens-1. Microvasc Res 63:70-80

43. Sajja RK, Prasad S, Cucullo L (2014) Impact of altered glycaemia on bloodbrain barrier endothelium: an in vitro study using the hCMEC/D3 cell line. Fluids Barriers CNS 11:8
44. Sobczak A, Golka D, Szoltysek-Boldys I (2004) The effects of tobacco smoke on plasma alpha- and gamma-tocopherol levels in passive and active cigarette smokers. Toxicol Lett 151:429-437

45. Dietrich M, Block G, Norkus EP, Hudes M, Traber MG, Cross CE et al (2003) Smoking and exposure to environmental tobacco smoke decrease some plasma antioxidants and increase gamma-tocopherol in vivo after adjustment for dietary antioxidant intakes. Am J Clin Nutr 77:160-166

46. Willcox JK, Ash SL, Catignani GL (2004) Antioxidants and prevention of chronic disease. Crit Rev Food Sci Nutr 44:275-295

47. Masubuchi T, Koyama S, Sato E, Takamizawa A, Kubo K, Sekiguchi M et al (1998) Smoke extract stimulates lung epithelial cells to release neutrophil and monocyte chemotactic activity. Am J Pathol 153:1903-1912

48. Ambrose JA, Barua RS (2004) The pathophysiology of cigarette smoking and cardiovascular disease: an update. J Am Coll Cardiol 43:1731-1737

49. Abbruscato TJ, Lopez SP, Mark KS, Hawkins BT, Davis TP (2002) Nicotine and cotinine modulate cerebral microvascular permeability and protein expression of ZO-1 through nicotinic acetylcholine receptors expressed on brain endothelial cells. J Pharm Sci 91:2525-2538

50. Hawkins BT, Abbruscato TJ, Egleton RD, Brown RC, Huber JD, Campos CR et al (2004) Nicotine increases in vivo blood-brain barrier permeability and alters cerebral microvascular tight junction protein distribution. Brain Res 1027:48-58

51. Lockman PR, McAfee G, Geldenhuys WJ, Van der Schyf CJ, Abbruscato TJ, Allen DD (2005) Brain uptake kinetics of nicotine and cotinine after chronic nicotine exposure. J Pharmacol Exp Ther 314:636-642

52. Livak KJ, Schmittgen TD (2001) Analysis of relative gene expression data using real-time quantitative PCR and the 2(-Delta Delta C(T)) Method. Methods 25:402-408

\section{Submit your next manuscript to BioMed Central and take full advantage of:}

- Convenient online submission

- Thorough peer review

- No space constraints or color figure charges

- Immediate publication on acceptance

- Inclusion in PubMed, CAS, Scopus and Google Scholar

- Research which is freely available for redistribution

Submit your manuscript at

www.biomedcentral.com/submit

C Biomed Central 